\title{
Biology and Culture of
}

Asian Seabass Lates calcarifer

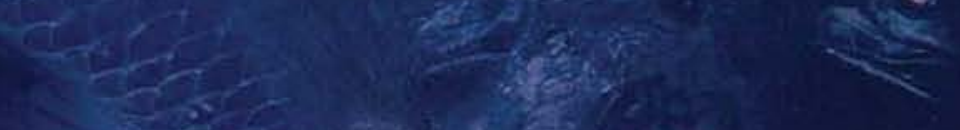

Editor

Dean R. Jerry
(CB.C) CRC Press Taylor \& Francis Group 


\section{Biology and Culture of Asian Seabass Lates calcarifer}





\title{
Biology and Culture of Asian Seabass Lates calcarifer
}

\author{
Editor \\ Dean R. Jerry \\ Centre for Sustainable \\ Tropical Fisheries and Aquaculture \\ School of Marine and Tropical Biology \\ James Cook University \\ Townsville, QLD \\ Australia
}

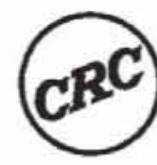

CRC Press

Taylor \& Francis Group

Boca Raton London New York

CRC Press is an imprint of the

Taylor \& Francis Group, an informa business

A SCIENCE PUBLISHERS BOOK 
CRC Press

Taylor \& Francis Group

6000 Broken Sound Parkway NW, Suite 300

Boca Raton, FL 33487-2742

(C) 2014 Copyright reserved

CRC Press is an imprint of Taylor \& Francis Group, an Informa business

No claim to original U.S. Government works

Printed in the United States of America on acid-free paper

International Standard Book Number: 978-1-4822-0807-8 (Hardback)

This book contains information obtained from authentic and highly regarded sources. Reasonable efforts have been made to publish reliable data and information, but the author and publisher cannot assume responsibility for the validity of all materials or the consequences of their use. The authors and publishers have attempted to trace the copyright holders of all material reproduced in this publication and apologize to copyright holders if permission to publish in this form has not been obtained. If any copyright material has not been acknowledged please write and let us know so we may rectify in any future reprint.

Except as permitted under U.S. Copyright Law, no part of this book may be reprinted, reproduced, transmitted, or utilized in any form by any electronic, mechanical, or other means, now known or hereafter invented, including photocopying, microfilming, and recording, or in any information storage or retrieval system, without written permission from the publishers.

For permission to photocopy or use material electronically from this work, please access www.copyright.com (http:/ / www.copyright.com/) or contact the Copyright Clearance Center, Inc. (CCC), 222 Rosewood Drive, Danvers, MA 01923, 978-7508400. CCC is a not-for-profit organization that provides licenses and registration for a variety of users. For organizations that have been granted a photocopy license by the CCC, a separate system of payment has been arranged.

Trademark Notice: Product or corporate names may be trademarks or registered trademarks, and are used only for identification and explanation without intent to infringe.

Visit the Taylor \& Francis Web site at http://www.taylorandfrancis.com

CRC Press Web site at http://www.crcpress.com
Science Publishers Web site at http://www.scipub.net 


\section{Preface}

The Asian seabass (Lates calcarifer) is an euryhaline fish species within the Family Latidae that is distributed from the Persian Gulf, throughout southeast Asia, India, northern Australia, Papua New Guinea and the western Pacific. Throughout its range the species has many common names including barramundi (Australia), plakapong (Thailand), koduva (Sri Lanka), kalaanji (Malaysia), pandugappa and chonak (India), apahap (Philippines) and siakap (Indonesia), to name but a few, and is of significant cultural and economic importance, both as an important fishery, as well as being increasingly commercially farmed.

As well as the species' economic importance, due to its relatively unique life-history whereby the species exhibits protandry (sex reverts from male to female as it ages), is catadromous (spawns in marine conditions and then may undergo part of its juvenile development in freshwater), whilst also being an ecologically important keystone predator species, L. calcarifer has received substantial scientific attention. Consequently, there has been a plethora of publications generated on the genetics, ecology, physiology, and aquaculture of $L$. calcarifer. However, to date, there has been neither scientific synthesis nor embodiment of information on this species' biology and ecology, as well as its aquaculture exploitation. The aim of this book therefore was to bring together the accumulated knowledge on L. calcarifer that is current and in a form that can be easily accessed by biologists, aquaculturists and university students. Of particular emphasis in the book is the science behind aquaculture of this species, as interest in farming of L. calcarifer is rapidly increasing with the species now commonly farmed outside its natural range in North America, Europe and southern Australia.

Finally, as a note to readers, a large body of the scientific knowledge related to the biology, ethylogy and ecology of L.calcarifer is derived from Australian research and as the book was being edited and compiled it became very obvious that Australian seabass populations may not be indicative of the wider species as whole. There presently are critical knowledge gaps for L. calcarifer in south-east Asia and other parts of its distribution. Anecdotal reports exist of populations which are purely marine, 
are not completely protandrous and that exhibit different morphology and / or behaviour. Therefore the editor feels that it is critical in the future that more scientific effort is devoted to understanding the species outside of Australia. This is essential not only for the conservation of the species, but also deeper understanding may identify traits and characteristics useful for aquaculture exploitation.

\section{Acknowledgements}

I thank all those people who have assisted in making this publication possible. First of all I would like to thank all the chapter contributors for their time and effort and for sharing their substantial knowledge on particular aspects of $L$. calcarifer. I also would like to thank all the external reviewers that took the time to review chapters and provide useful comments. These include Jeremy van der Waal, Igor Pirozzi, Kyall Zenger, Jose Domingos, and Brad Pusey. Also a big thanks to Erica Todd for her tireless editing of chapters and formatting of the bibliographies and to Felix Ayson for his initial help with pulling together the chapters and other valuable contributions.

Dean R. Jerry 


\section{Contents}

Preface v

1. Taxonomy and Distribution of Indo-Pacific Lates 1 Rohan Pethiyagoda and Anthony C. Gill

2. Early Development and Seed Production of Asian Seabass, Lates calcarifer

Evelyn Grace De Jesus-Ayson, Felix G. Ayson and Valentin Thepot

3. Climate Effects on Recruitment and Catch Effort of Lates calcarifer Jan-Olaf Meynecke, Julie Robins and Jacqueline Balston

4. Reproductive Biology of the Asian Seabass, Lates calcarifer

Evelyn Grace De Jesus-Ayson and Felix G. Ayson

5. Lates calcarifer Wildstocks: Their Biology, Ecology and Fishery

D.J. Russell

6. Infectious Diseases of Asian Seabass and Health

102

Management

Kate S. Hutson

7. The Genetics of Asian Seabass

Dean R. Jerry and Carolyn Smith-Keune

8. Lates calcarifer Nutrition and Feeding Practices Brett Glencross, Nick Wade and Katherine Morton

9. Post-Harvest Quality in Farmed Lates calcarifer Alexander G. Carton and Ben Jones

10. Farming of Barramundi/Asian Seabass: An Australian Industry Perspective Paul Harrison, Chris Calogeras and Marty Phillips 
viii Biology and Culture of Asian Seabass

11. Nursery and Grow-out Culture of Asian Seabass,

Lates calcarifer, in Selected Countries in Southeast Asia

Felix G. Ayson, Ketut Sugama, Renu Yashiro and

Evelyn Grace de Jesus-Ayson

12. Muscle Proteins in Asian Seabass-Parvalbumin's Role

293 as a Physiological Protein and Fish Allergen

Michael Sharp and Andreas L. Lopata

Index

307

Color Plate Section 